\title{
Lifetime Prolongation of ICRF Generators, Theoretical and Conceptual Aspects
}

\author{
F. Pompon, H. Fuenfgelder, H. Faugel and the IPP ICRF team \\ Max-Planck-Institut für Plasmaphysik, EURATOM Association, D-85748 Garching, Germany
}

\begin{abstract}
Two ICRF generators, previously used for ASDEX and W7-AS, have been designed almost 30 years ago [1], based on technology and components available at that time. Four, more recent generators used by ASDEX Upgrade, are an evolutionary development. Today, two out of three tetrodes used in the amplifier line up are obsolete and spares are becoming scarce. Based on the long experience gained with the initial configuration, a redesign process has been started aiming to significantly prolong lifetime of the generators. Each of the four amplification stages required to reach $2 \mathrm{MW}$ output power is undergoing a more or less severe modification. The most critical change concerns the final amplification stage and has already been successfully implemented [2], whereas changes of the remaining stages are on-going. A new, FET based first stage, provides a higher output power in order to drive the following (pre-driver) stage where a triode is replacing the initial tetrode. The tube of the third (driver) stage is upgraded to a higher power dissipation capability, to increase the drive power for the fourth (final) stage. One of the two generators formerly used for ASDEX and W7-AS has been modified along those lines.
\end{abstract}

Keywords: ICRF, generator, vacuum tube.

PACS: 52.50.Qt, 84.30.Le, 84.47.+w.

\section{INTRODUCTION}

A total of six ICRF generators is installed at IPP Garching. Four of them are routinely used for ASDEX Upgrade experiments, whereas the two other generators have not been in service since W7-AS was closed in 2002. All generators built in the 80 s [1] have basically the same structure. Nowadays, two of the three vacuum tubes used are not manufactured anymore and spares are becoming scarce. To overcome this obsolescence, a redesign of all amplification stages, using perennial solutions, has been started. After having given a general description of the ICRF generator at ASDEX Upgrade, this paper highlights stage by stage the conceptual modifications we propose.

\section{GENERAL DESCRIPTION OF THE 2 MW RF GENERATOR}

As shown in Figure 1, there are four amplification stages lined up: a solid-state amplifier and three vacuum tube based amplification stages. The RF input signal is fed into the solid-state amplifier via a PIN-diode regulator to permit adjustment of input level with respect to the selected output level. Twelve motor-driven tuning elements, variable vacuum capacitors or sliding lines, allow a usable frequency range of 30 to $120 \mathrm{MHz}$. Direct coupling from pre-driver to driver is achieved by a phi network, 


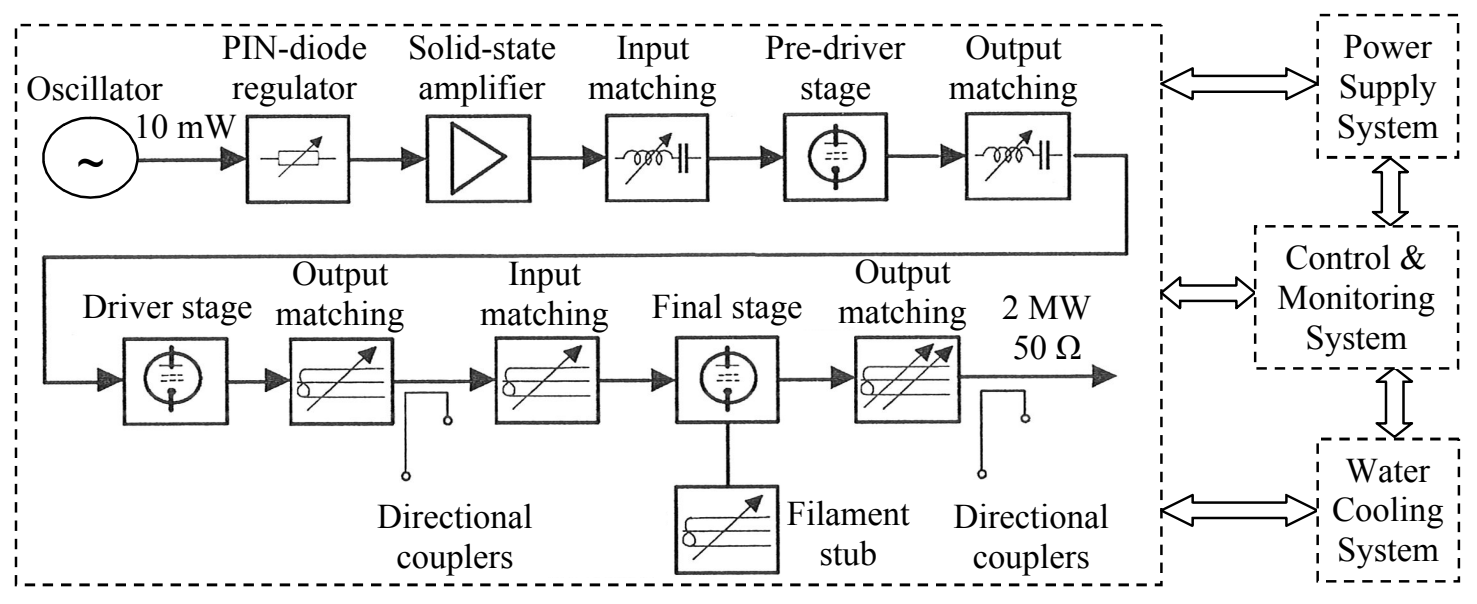

FIGURE 1. Synopsis of the high power RF generator

whereas interface from driver to final is a $50 \Omega$ interface formed by a 6 " coax line. A variety of power supplies is required to feed, grid, screen and anode of all tubes. As dissipated power is significant, about $1 \mathrm{MW}$ at the anode of final stage, a reliable water cooling system is mandatory. By monitoring operating parameters, the control system avoids unsafe conditions for tubes. An ignitron based crowbar system is installed, in case a fast shutdown is required.

\section{FINAL STAGE}

The initial final stage tetrode (CQK650-2) was manufactured by the BBC Company. In the early 90s, Thomson acquired the BBC Company and decided to discontinue production of this tube in the late 90s. After having run out spare tubes and with only a limited number of rebuilding cycles, IPP decided in 2008 to initiate the replacement of the final tube by a CPI/ Eimac 4CM2500KG. In 2010, this final stage conversion was successfully implemented for one of the two generators formerly used for W7-AS. This work was realized through a close and fruitful collaboration with ITER India, taking advantage of the General Atomics' experience in a similar exercise. A complete overview of this project is detailed in [2].

\section{DRIVER STAGE}

The final stage modification has impacted the output requirement of the driver stage which has to deliver up to $150 \mathrm{~kW}$. The initial driver tube, a CPI/Eimac 8959, is capable to deliver this RF power, however there is little margin. In order to improve reliability and lifetime, it will be replaced by a mechanically modified version of the $\mathrm{CPI} /$ Eimac $4 \mathrm{CW} 150.000 \mathrm{E}$, requiring no modification to the cavity. Additionally it allows running driver and final up to $22 \mathrm{kV}$ commonly on a single high voltage power supply. 


\section{PRE-DRIVER STAGE}

Initially provided by Siemens, the RS1054 tube is no longer manufactured and will be replaced by a CPI/Eimac YU-191B triode. An important choice criterion is that this tube is widely used in RF generators for the semiconductor industry, insuring a longterm availability at a competitive price. The implementation of this replacement tube into the pre-driver stage can be achieved in a very simple way, as the screen grid power supply is logically removed (no screen grid for a triode) as well as the control grid power supply (grounded-grid configuration at zero bias). This triode doesn't necessarily need a tube socket as it's mounting bracket can be directly bolted to generator chassis. A new filament transformer $(7.5 \mathrm{~V} / 51.5 \mathrm{~A})$ is required. Table 1 illustrates a comparison of operating parameters for both tubes, based on electrical characteristics analysis provided in datasheets [3] and [4]. These calculations show that the YU-191B tube is capable to deliver more than the required of output power $(4.5 \mathrm{~kW})$ at very reasonable anode dissipation. Moreover, the $50 \Omega$ input resistance of the tube will ease the input matching.

TABLE 1. Operating parameters calculation using electrical characteristics for both tubes.

\begin{tabular}{|c|c|c|c|c|c|c|c|c|c|c|}
\hline & \multicolumn{3}{|c|}{ Settings } & \multicolumn{7}{|c|}{ Calculated parameters } \\
\hline & $\begin{array}{c}\mathbf{V}_{\text {A DC }} \\
(\mathbf{V})\end{array}$ & $\begin{array}{c}\mathbf{V}_{\text {G2 DC }} \\
\text { (V) }\end{array}$ & $\begin{array}{c}\mathbf{V}_{\text {G2 DC }} \\
\text { (V) }\end{array}$ & $\begin{array}{l}P_{\text {drive }} \\
\text { (W) }\end{array}$ & $\begin{array}{l}\mathbf{P}_{\text {out }} \\
(\mathbf{W})\end{array}$ & $\begin{array}{l}\mathbf{P}_{\mathrm{Adiss}} \\
\text { (W) }\end{array}$ & $\begin{array}{c}\eta \\
(\%)\end{array}$ & $\begin{array}{l}\text { Gain } \\
\text { (dB) }\end{array}$ & $\begin{array}{l}R_{\text {in }} \\
(\Omega)\end{array}$ & $\begin{array}{l}\mathbf{R}_{\mathbf{A}} \\
(\boldsymbol{\Omega})\end{array}$ \\
\hline RS1054 & 5000 & -55 & 500 & 60 & 4340 & 2660 & 62 & 18,6 & 21,4 & 1843 \\
\hline YU-191B & 5000 & 0 & NA & 325 & 6480 & 2820 & 69 & 13 & 49,9 & 1562 \\
\hline
\end{tabular}

\section{SOLID-STATE AMPLIFIER}

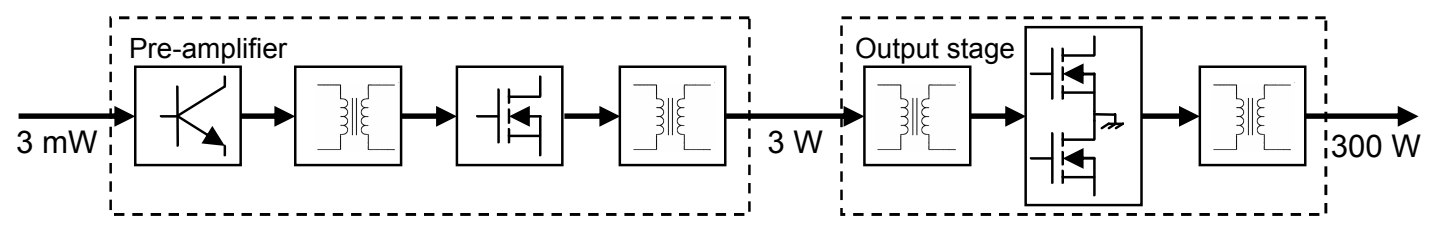

FIGURE 2. Synopsis of the solid-state amplifier
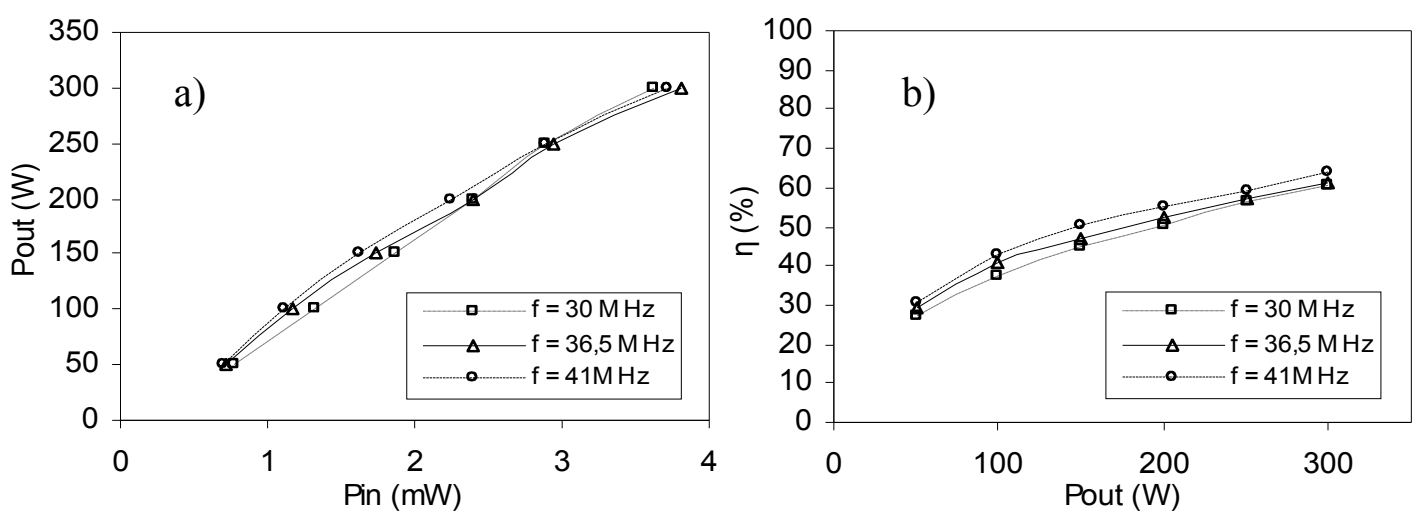

FIGURE 3. Characterization of the solid-state amplifier. (a) Linearity. (b) Efficiency. 
In order to meet the input requirement of the new the pre-driver tube, a solid-state amplifier, replacing the initial ENI3100L amplifier was designed and tested. Figure 2 shows the line up of two stages, followed by a LDMOS based push pull output stage, providing up to $300 \mathrm{~W}$ within the frequency range of 20 to $65 \mathrm{MHz}$. Performances of the amplifier at frequencies of most interest for ASDEX Upgrade are presented in Figure 3. Up to $300 \mathrm{~W}$ of RF output power, the amplifier shows good linearity with a gain close to $50 \mathrm{~dB}$. The efficiency of the output stage reaches a value typical for a push-pull (class B) configuration.

\section{AVAILABLE VS. REQUIRED INPUT POWERS}

TABLE 2. Required input power for $2 \mathrm{MW}$ output and the available input power for every stage.

\begin{tabular}{|c|cc|}
\cline { 2 - 3 } \multicolumn{1}{c|}{} & $\begin{array}{c}\text { Required } \\
\text { input power }\end{array}$ & $\begin{array}{c}\text { Available } \\
\text { input power }\end{array}$ \\
\hline Pre-amplifier & $2.25 \mathrm{~mW}$ & $10 \mathrm{~mW}$ \\
Output stage & $2.25 \mathrm{~W}$ & $5 \mathrm{~W}$ \\
Pre-driver stage & $225 \mathrm{~W}$ & $300 \mathrm{~W}$ \\
Driver stage & $4.5 \mathrm{~kW}$ & $6 \mathrm{~kW}$ \\
Final stage & $150 \mathrm{~kW}$ & $200 \mathrm{~kW}$ \\
\hline
\end{tabular}

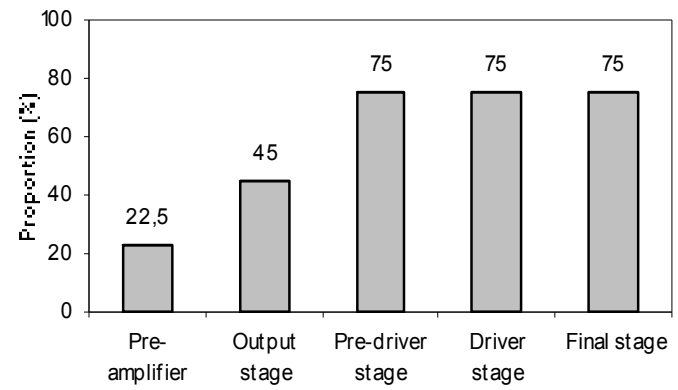

FIGURE 4. Proportion of the available input power required for $2 \mathrm{MW}$ output power.

All modifications brought to the generator have impacted the input levels balance between stages. Table 2 summarizes the input levels required for $2 \mathrm{MW}$ of output power and allows the comparison with the available levels for every stage. Reprocessed in Figure 4, these data show that, in terms of proportion of available power, a comfortable power margin is present at all amplification stages.

\section{CONCLUSION \& STATUS}

The lifetime of ICRF generators is dependent of the tube's market. Replacement vacuum tubes must be chosen according to their long term availability, insuring equivalent or even better performances. Our study demonstrates that the lifetime of ICRF generators can be prolonged, using the following successful keys: state of the art technology, simple configuration, power margin, reliability and competitive cost. The solid-state amplifier and the final stage have been successfully implemented, whereas components for the remaining stages are in house and will be installed and tested soon.

\section{REFERENCES}

1. W. Schminke et al., "The 1.5 MW ICRF heating generators for ASDEX and W VII", $10^{\text {th }}$ Symposium on Fusion Engineering, 1498-501, Philadelphia (1983).

2. H. Fünfgelder et al., "Lifetime Prolongation of ICRF Generators, Practical Aspects and Results", this conference.

3. Siemens Company, "RS1054 datasheet".

4. Eimac division of Communications and Power Industries, "YU-191B datasheet". 